\title{
Evaluating a Self-Charging Electrostatic Dust Shield for Solar Cell applications in Baghdad Outdoor Weather
}

\author{
Evaluación de un protector antipolvo electrostático de carga \\ automática para aplicaciones de células solares en el clima \\ exterior de Bagdad
}

Author:

Manal Midhat Abdullah ${ }^{1}$

Jamal H. Al-Ani' ${ }^{2}$

Shima K. Abdulridha ${ }^{3}$

Mazin Al- Ansari ${ }^{4}$

\section{SCIENTIFIC RESEARCH}

How to cite this paper:

Abdullah M., Al-Ani J. Abdulridha S., Ansan M., Evaluating a Self-Charging Electrostatic Dust Shield for Solar Cell applications in Baghdad Outdoor Weather, Baghdad, Iraq. Innovaciencia 2019; 7 (1): 1-8. http://dx.doi.org/10.15649/2346075X.788

Reception date:

Received: 25 February 2019

Accepted: 30 April 2019

Published: 25 October 2019

Keywords:

dust removing, electro-dynamic discharge, clearing factor, solar cell.

\begin{abstract}
Introduction: It is well known that the biggest problem facing the utilizing of solar cell Panels in Baghdad is the unpredictable dusty weather through the days of year. This big problem is not easy to overcome due to the frequent dust accumulations and the high cost of cleaning and other maintenance problems. Dust problems are increasing due to global warming. In Baghdad city, where solar radiation is intense and available almost throughout the year, Deposition of dust on the panels could severely minimize solar-to power output efficiency. There are many methods for dust removing from surfaces like the natural dust removal of wind, mechanical dust removing, super-hydrophobic on solar panel surface, and the electrostatic method which is adopted in this work. The dust particles will be charged statistically by rolling on the surface of the solar panels they will have the same electric charge and the electrostatic forces between them are repulsion. Hence, the dust particles will float away from the solar panels. Materials and Methods: A self-charging transparent conductive glass is prepared by spraying a thin film (141 nm thickness) of a Tin dioxide $\left(\mathrm{SnO}_{2}\right)$ solution on a glass substrate $\left(12 \times 12 \mathrm{~cm}^{2}\right.$. The dust shield is connected to an electronic charging circuit. The shield is located on the top of a silicon solar cell. The novel idea is that the shield is electrically supplied by the solar cell itself whereas D.C. current from the solar cell itself is used to charge the conductive glass, which is located on the top surface of the cell. Results and Discussion: A test was done for dust removing from a Silicon solar cell by electrostatic repulsion method, considering matching the spectral response region of the Silicon solar cells with the film transmittance spectral region $(400-700 \mathrm{~nm})$. The transmittance value is between $(92-95) \%$ and results are compared with an identical reference solar cell. Results show a good response as the calculated clearing factor value increases due to the cell efficiency increment. Also, the clearing factor is discussed as a function of outdoor temperature to show a direct proportionality, while the environmental humidity showed an inverse proportionality. Conclusions: A self-cleaning method for a solar cell is successfully introduced via a conductive glass. tests were carried outdoor in Baghdad city. Results showed that there is a direct proportionality between both: the clearing factor and the efficiency gain with the ambient temperature. The ambient humidity showed indirect proportionality with system efficiency (clearing factor and efficiency gain show reduction as the humidity percentage increases).
\end{abstract}

\footnotetext{
Uni. of Baghdad/ College of Science, Dep. of Physics, Baghdad, Iraq, manal.madhat@yahoo.com

Renewable Energy and Environment Research Center, Baghdad, Iraq, jamalani25@yahoo.com

Renewable Energy and Environment Research Center, Baghdad, Iraq, maserlaseropics2013@gmail.com

4 Uni. of Baghdad/ College of Science, Dep. of Physics, Baghdad, Iraq, mazinalansari@yahoo.com
} 


\section{INTRODUCTION}

It is well known that the biggest problem facing the utilizing of solar cell Panels in Baghdad is the unpredictable dusty weather through all the days of year. This big problem is not easy to overcome due to the frequent dust accumulations and the high cost of cleaning and other maintenance problems. Dust problems are increasing because of the global warming.

As discussed in a previous study the dust contains different compounds, such as: Mineral dusts ( $\mathrm{Ca}$, Sn, Zn, Cu, Ni, Cr, As, Ti, Fe, Zr, Ga, Rb, Sb, Si) ${ }^{(1)}$ in addition to the organic and vegetable dusts ( such as flour, spores, wood, and cotton pollens).

Deposition of dust on the panels, particularly in dusty areas could severely minimize solar-to power output efficiency ${ }^{22}$. In Baghdad city, where solar radiation is intense and available almost throughout the year, obscuration of solar radiation is mainly caused by dust which causes a significant problem. Solar panel obscuration by dust is caused by: (1) suspended dust in the atmosphere (aerosol) that is directly in the optical path of incoming radiation to the solar panels, causing extinction of light even when the cells are relatively clean, and (2) extinction of light due to dust deposited on the panel surface $\frac{(3)}{\text {. }}$ Both conditions occur during high dust concentration in the atmosphere. Dust storms can completely obscure solar radiation ${ }^{(4)}$.

There are many methods for dust removing from surfaces:

a- Natural Dust Removal: The only significant category of natural dust removal is wind clearing. bMechanical Dust Removal: refer to implementing automatic equipment to clean the solar panel surfaces including brushing, shaking, shocking, sweeping and vibrating the solar panels. c- Super-hydrophobic / Super- hydrophilic solar panel surface. Among thesemethod is the electrostatic method, in 1971 (5) studied the dust mitigation strategy that works on the lunar surface. They suggested that there are possibly two mechanisms of particles charging: 1. triboelectric charging. 2. Photoemission of electrons from the surface of the particles by radiation. So, if there is a high potential on the surface of the solar panels, the charged and uncharged dusts will be attracted to the panels because of electrostatic forces (Van der Waals forces between rigid bodies states: When two particles are brought into contact, they are subjected to capillary, electrostatic and van der Waals forces). Capillary forces are caused by condensed moisture on the surface of the particle. Electrostatic forces depend on the charges present in the particles ${ }^{(6)}$. The dust particles will be charged statistically by rolling on the surface of the solar panels they will have the same electric charge and the electrostatic forces between them are repulsion. Hence, the dust particles will float away from the solar panels.

The most popular electro dust removal technology is based on the electric curtain concept developed by F.B. Tatom and collaborators at NASA in 1967 and further developed by Masuda at the University of Tokyo in the 1970s $\frac{(7)}{7}$. This technique has proven to lift, and transport charged and uncharged particles using electrostatic and dielectrophoretic forces $\frac{(8)}{\text {. }}$ From equation (1) The net force of repulsion on the dust particles, which elevates them abo.ve the surface of glass, can be expressed as the contribution from the electro-dynamic force, the viscous force, and the gravitational force ${ }^{(5)}$ :

$$
M \frac{d^{2} r}{{d t^{2}}^{2}}=q E \cos \boldsymbol{\omega t}-6 \pi \boldsymbol{\eta} \frac{\mathrm{dr}}{\mathrm{dt}}-\mathrm{mg} \ldots \ldots \ldots
$$

Where (m) is the dust particle mass, ( $r$ ) is the particle's position, $(\eta)$ is the viscosity of the fluid in which the dust particles move, (q) is the dust particle charge, and $(\mathrm{g})$ is the acceleration due to gravity. 
Due to the complicated nature of the particle-field interaction, where the motion of the dust particles is nonlinear and coupled, this equation of motion cannot be solved analytically. Masuda proposed a solution to a linear approximation to the equation of motion assuming small oscillations for the particle as shown in equation (2):

$$
\sum_{n=i} m_{i} \frac{d^{2} r_{i}}{{d t^{2}}^{2}}=(n e) * \frac{v}{d}-6 \pi \eta \frac{d r}{d t}-m_{i} g \sin \theta
$$

Where (n) is the number of dust particles, (m) is the mass of the rolling dust particle, (r) is the particle's position, (v) is the voltage applied to the surface of the thin film, (d) is the diameter of the dust particles, $(\eta)$ is air viscosity, and $(\theta)$ is the angle of tilting system $\stackrel{(7)}{ }$.

Dust particles are statically charged in nature ${ }^{(8)}$. The aim of this research is generating a repulsive force between the accumulated dust particles and the charged surface. The repulsive force helps in cleaning the surface of the system. The charged particles will repel and roll down the surface affected by their weight, and uncharged particles will be charged by conduction and role down also.

\section{MATERIALS AND METHOD}

A self-charging transparent conductive glass is prepared by spraying a thin film of a Tin dioxide $\left(\mathrm{SnO}_{2}\right)$ on a glass sheet as shown in fig. 1. The prepared thin film showed high transparency in the spectral response region of the silicon solar cell, a good adhesion with the glass, economic, and stable in different weather conditions.

a D.C. current from the solar cell itself is used to charge the conductive glass, which is located on the top surface of the cell. It is worth to say that $0.01 \%$ of the solar cell's output current is taken for charging the conductive glass. This ratio is achieved as follows: we took the negative pole of the solar cell (-ve charge) to connect it to the conductive glass, so the surface of the glass is negatively charged. The positive pole of the cell goes directly to the charging battery via voltage divider. We calculate the current on the conductive glass by applying the basic Ohm's law, ( $\mathrm{R}$ represents the measured resistivity of the conductive glass, $\mathrm{V}$ is the solar cell voltage, $\mathrm{A}$ is the current of the conductive glass).

\section{a. The deposition of the $\mathrm{SnO}_{2}$ layer:}

A transparent and homogenous $\mathrm{SnO}_{2}$ layer was deposited on the glass substrate using spray pyrolysis deposition technique from a chemical solution with the area of $\left(12 \times 12 \mathrm{~cm}^{2}\right)$ using spray pyrolysis deposition technique. The sprayed solution was then heated in furnace $\left(500{ }^{\circ} \mathrm{C}\right)$ to decompose $\mathrm{SnCl}_{4}$ into $\mathrm{SnO}_{2}$, According to the chemical equation:

$3 \mathrm{CH}_{3} \mathrm{OH}+\mathrm{SnCl}_{4} \longrightarrow \mathrm{SnO}_{2}+4 \mathrm{HCl}+\mathrm{CH}_{2} \mathrm{O}+2 \mathrm{CH}_{3}$

Figure (1) shows the $\mathrm{SnO}_{2}$ thin film.

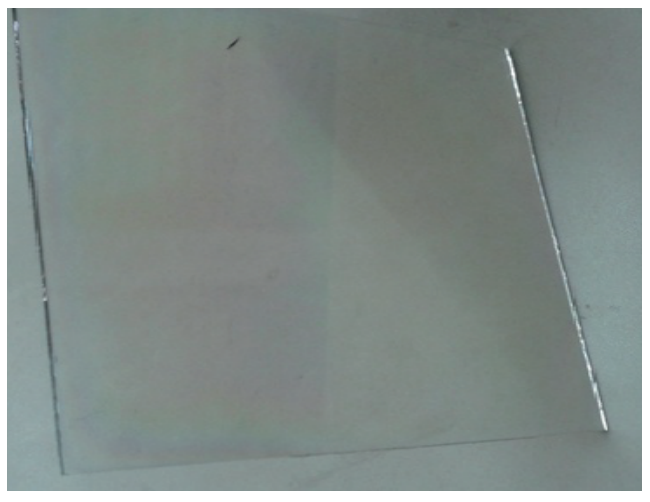

b. The electronic circuit

Fig.1. $\mathrm{SnO}_{2}$ thin film deposited on a glass sheet 
The electrical circuit consist of:

1- Solar panel to provide the direct current (DC).

2- Conductive glass to remove the dust particle from the surface of the solar panel.
3- Voltage regulator to control the voltage towards the rechargeable battery.

4- Load (DC motor) to discharge the rechargeable battery.

5- A rechargeable battery.

It is connected as shown in fig. (2)
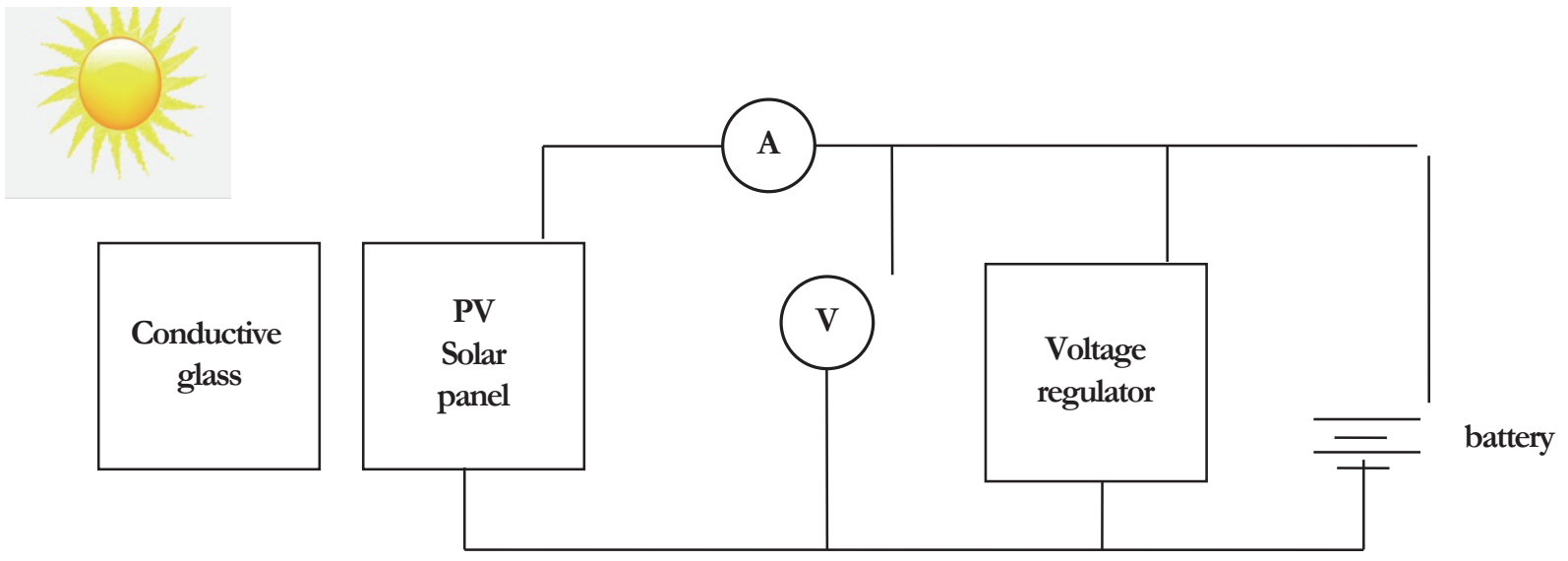

Fig (2). The electronic circuit diagram of the system

c. Experimental setup and the procedure of the dust cleaning

In order to test the efficiency of the electrostatic shield, two identical silicon solar cells were used. The first cell as a reference and the second cell was

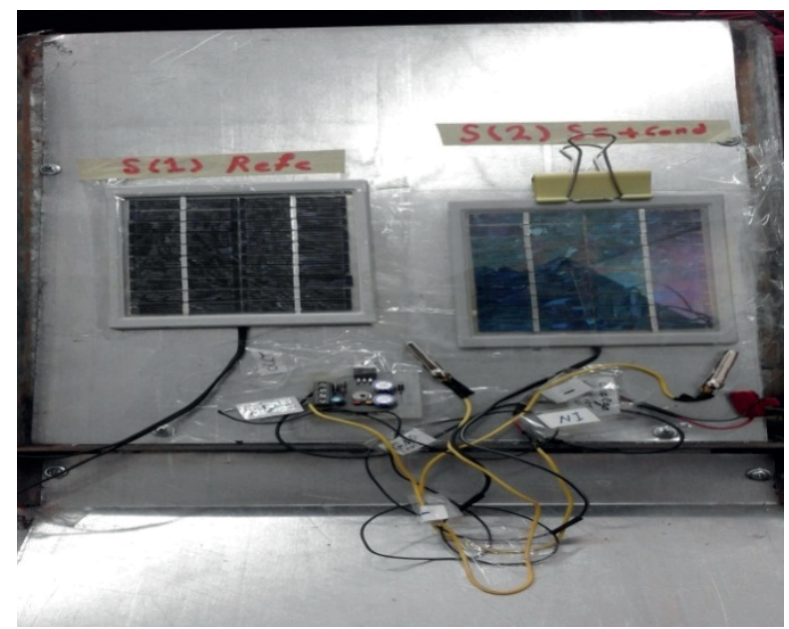

(a) covered with the electrostatic shield. Both cells were mounted on a tilted plate facing the sun radiation. The latter cell was energized by an electrical d-c current from the solar cell itself via a storage battery (Fig.3). Dust particles were allowed to deposit on both cells all along the experiment.

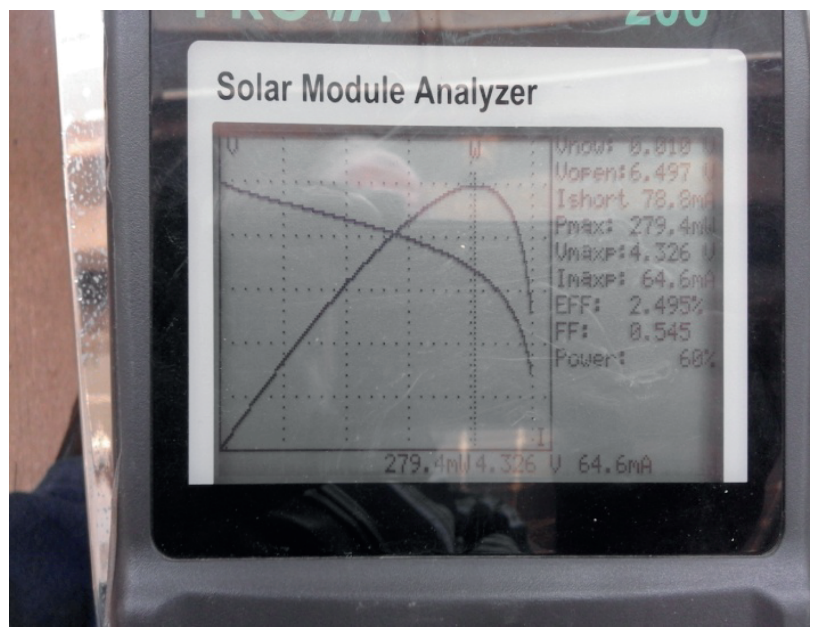

(b)

Fig. (3) (a). The setup of the system. (b). I- V characteristics of the system 


\section{RESULTS}

\section{a. Characterization of the $\mathrm{SnO}_{2}$ thin Film}

The optical microscope images of the sheet as shown in Fig. (4).

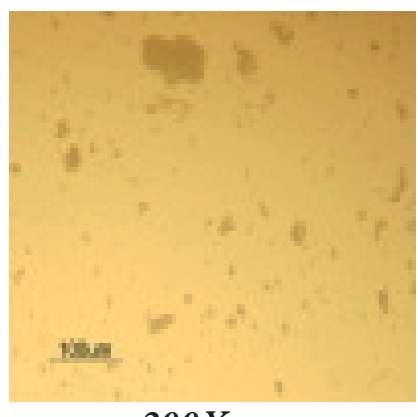

$200 X$

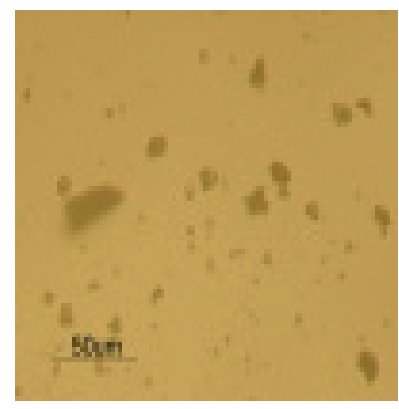

$500 X$

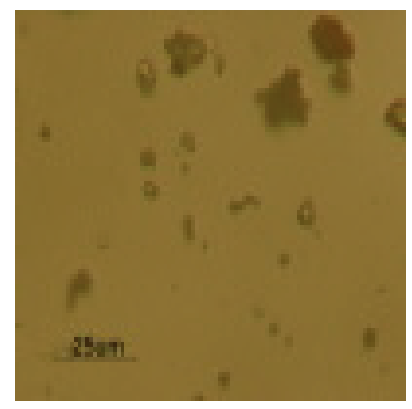

$1000 X$

Fig. (4). Optical microscope images of the sheet

AFM test surface morphology of the thin film $\left(\mathrm{SnO}_{2}\right)$ with average particle size of about 183.86

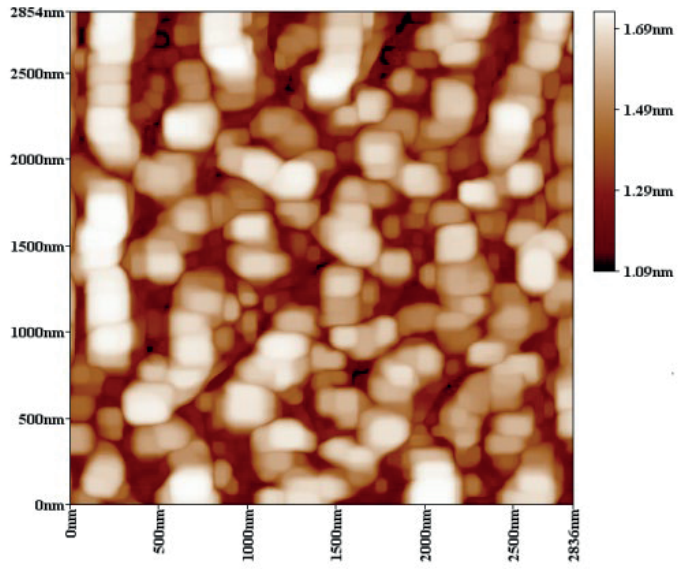

$\mathrm{nm}$, the average roughness of the sample is $2.43 \mathrm{~nm}$ as shown Fig (5).

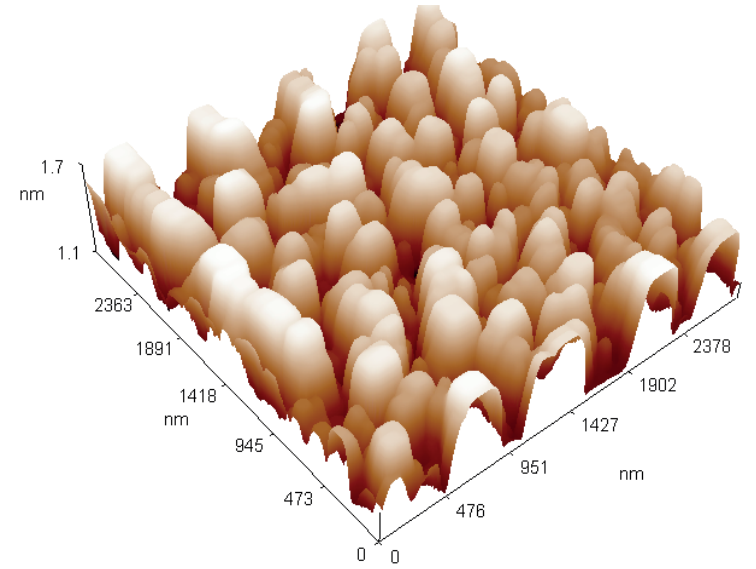

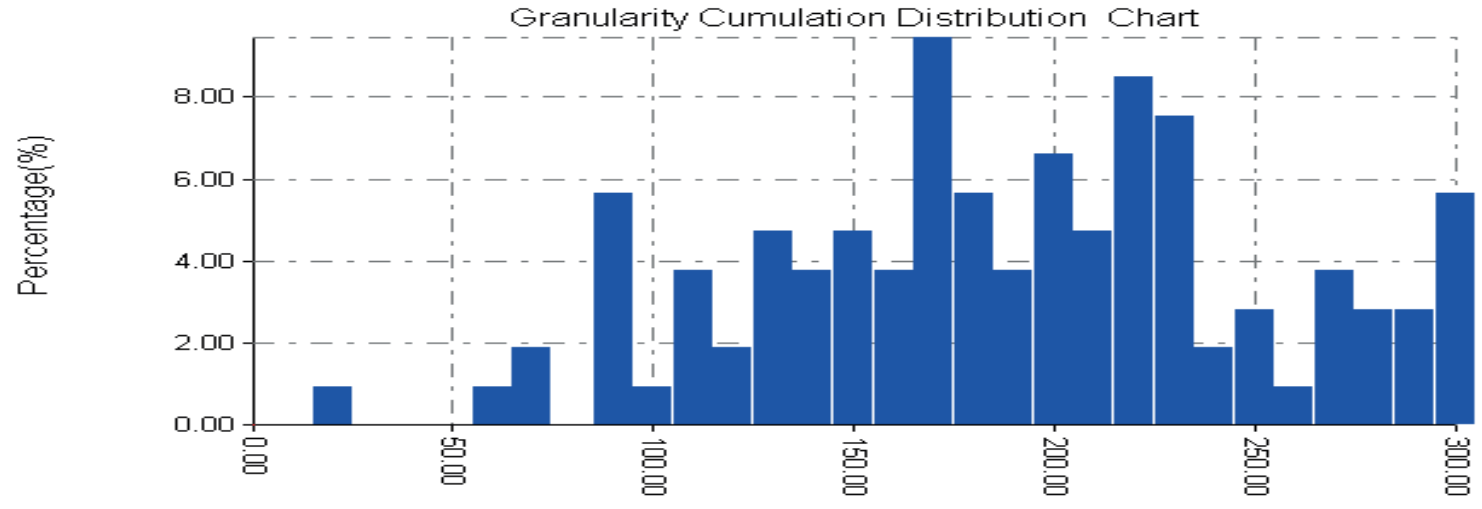

Diameter(nm)

Fig. (5). AFM test for the $\mathrm{SnO}_{2}$ thin film. 
The transmission spectrum of the $\left(\mathrm{SnO}_{2}\right)$ thin film is of the thin film is in the range $(94-98) \%$ as shown in the range (350-700) nm, the relative transmittance Fig (6).

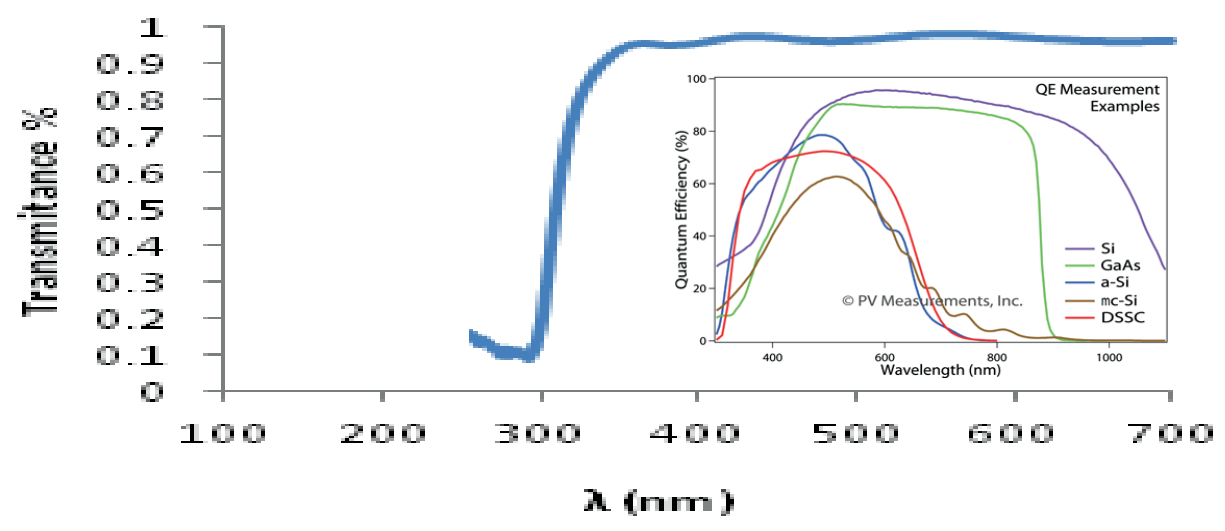

Fig. (6). The optical transmission spectrum of the $\mathrm{SnO}_{2}$ thin film. The response curve is taken from ref. ${ }^{(9)}$

\section{b. The Clearing Factor (C.F.)}

In order to numerically evaluate the dust removal from the solar cell, a factor called a clearing factor $(\mathrm{CF})$ is introduced. This factor represents the percentage of the dust that has been removed from the system after each experiment relative to the total dust [10].

C. F. $=\frac{\left(\mathrm{m}_{\mathrm{i}}\right)-\left(\mathrm{m}_{\mathrm{f}}\right)}{\left(\mathrm{m}_{\mathrm{i}}\right)} * 100 \% \ldots \ldots(4)$
Where: C.F.: Is the clearing factor $\mathrm{m}_{\mathrm{i}}$ : is the initial dust weight on the solar cell before charging the conductive thin film

$\mathrm{m}_{\mathrm{f}}$ is the dust weight that remained on the solar cell after the charging.

The clearing factor of the system is studied as a function of both the temperature and the humidity of ambient in Baghdad city for the period (May 20th till July 20th) 2017. Fig. (7) shows that the clearing factor (C.F.) is directly proportional to the temperature.

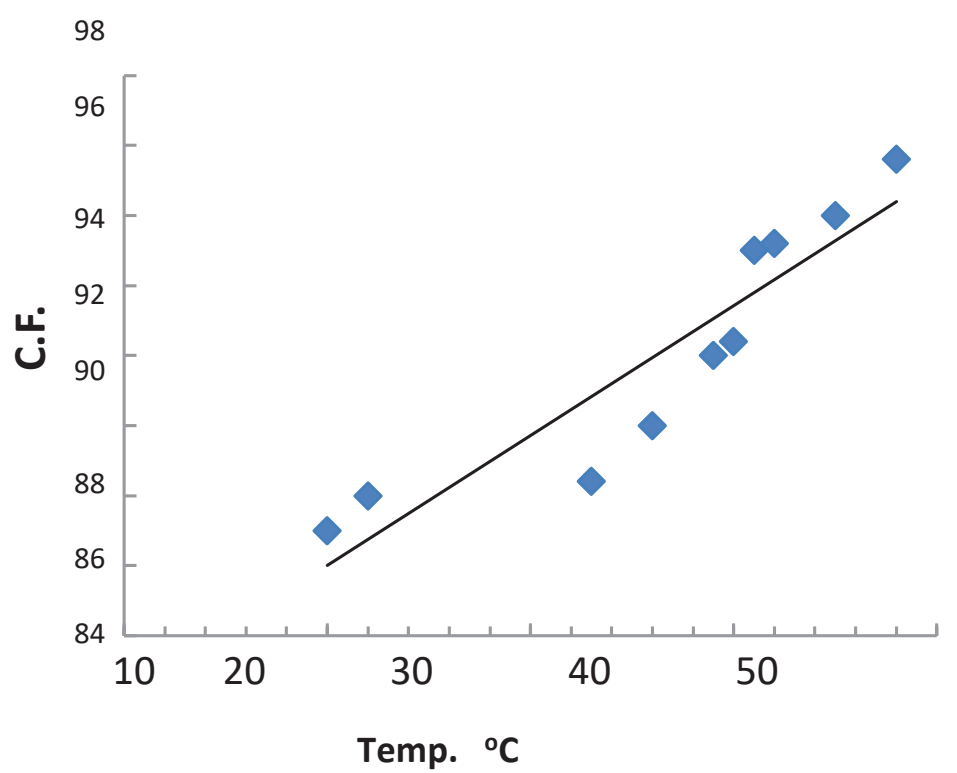

Figure (7). The clearing factor vs. the ambient temperature in Baghdad city. 


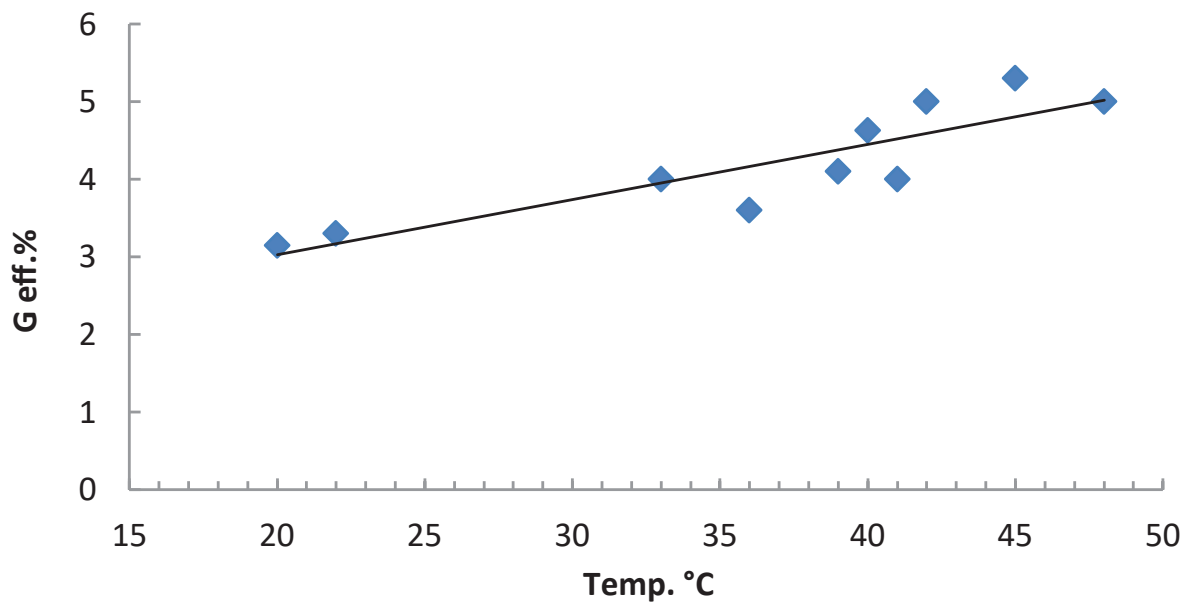

Fig. (8). The percentage of gain in the solar cell's efficiency vs. the ambient temperature in Baghdad city.

Figure (8): The percentage of gain in the solar cell's The ambient humidity is Adversely affecting the dust

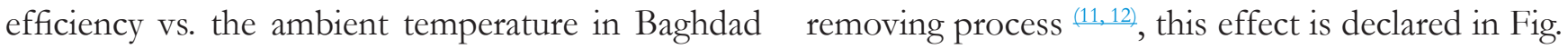
city. (9 and 10).

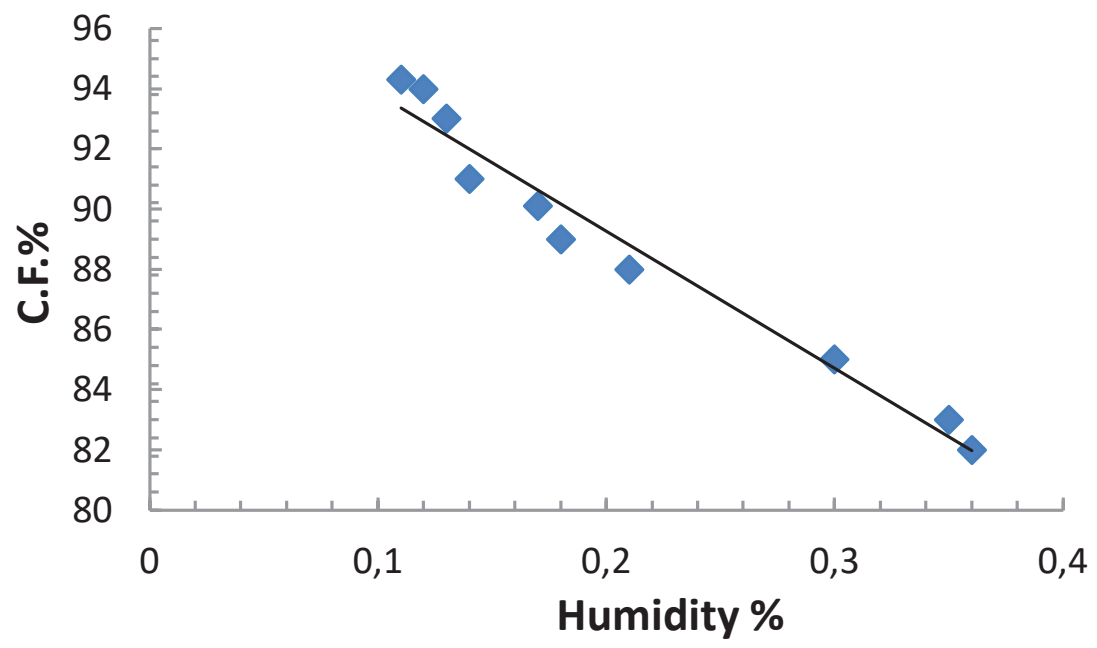

Figure (9). The clearing factor vs. environmental humidity for Baghdad city.

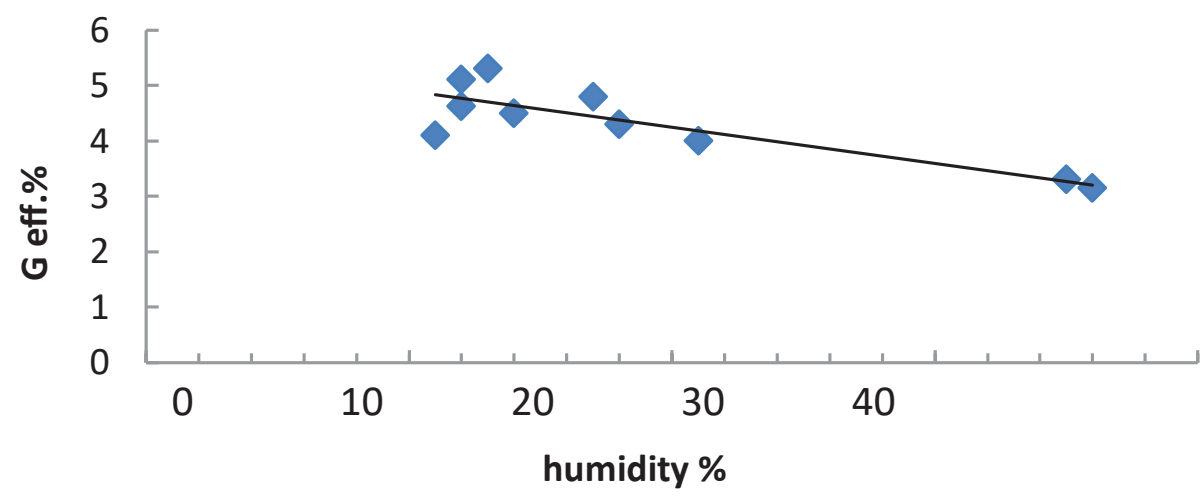

Figure (10). The percentage of gain in the solar cell's efficiency as a function of the ambient humidity in Baghdad city. 


\section{DISCUSSION}

The deposited dust gives a good indication for formation on the electrostatic glass sheet, for the film as shown in Fig. (5). This region is considered as the transparent region of the film which is very suitable to the response of many types of solar cells including the silicon solar cell as shown in Fig.(6).That is because the dust becomes drier and lighter with increasing the temperature, hence the dust removing process becomes more efficient as shown in Fig.(7). The direct proportionality declares the effective dust clearing process from the system as shown in Fig.(8). At relatively high humidity, the C.F. has low values, this is attributed to the capillary effect between the dust particles where the humidity makes the parti

cles pack together and become heavy in some way, the humidity factor also makes the particles adhere to the glass sheet, thereby hindering the process of removing dust. This reason also explains the relation between $\mathrm{G}_{\text {eff. }} \%$ and the humidity percentage as shown in Fig. $(9,10)$.

\section{CONCLUSIONS}

A self-cleaning method for a solar cell is successfully introduced via a conductive glass. The method depends the electro-static method for removing and preventing the dust and the airborne particulate from depositing on the surface of solar panels.

Tests were carried outdoor in Baghdad city. Results showed that there is a direct proportionality between both: the clearing factor and the efficiency gain with the ambient temperature. The ambient humidity showed indirect proportionality with system efficiency (clearing factor and efficiency gain show reduction as the humidity percentage increases).

\section{REFERENCES}

1. Abdullah M, et al. SnO2 Transparent Self- Cleaning Dust Shield for Solar Panels, International Journal of Application or Innovation in Engineering \& Management (IJAIEM).2013; 2.

2. Holmes, Hannah. The Secret Life of Dust. Wiley. 2001.

3. Svarosky L. Powder Testing Guide: Methods of Measuring the Physical Properties of Bulk Powders (Elsevier Applied Science, Oxford 1987.

4. Mazumder M, et al. Electrostatic Removal of Particles and its Applications to Self-Cleaning Solar Panels and Solar Concentrators, Department of Electrical and Computer Engineering, Boston University, Boston. 2011.

https://doi.org/10.1016/B978-1-4377-78854.10005-3

5. Masuda S and Aoyoma M. Characteristics of electric dust collector based on electric curtain, Proceedings of the General Conference of the Institute of Electronic Engineers, Japan, 1971, No. 821.

6. Krupp H. (1967), Adv. Colloid Interface Sci. 1 111.

https://doi.org/10.1016/0001-8686(67)80004-6

7. Calle C, et al. Dust particle removal by electrostatic and dielectrophoretic forces with applications to NASA exploration missions. Proc. ESA Annual Meeting on Electrostatics, 2008; 1.

8. Liu G, Marshall J. Particle transport by standing waves on an electric curtain, Journal of Electrostatics. 2010; 68: 289.

https://doi.org/10.1016/j.elstat.2010.02.004

9. PV measurements, inc, WA USA, pvmsales@ pvmeasurements.com.

10. Abdullah M, e.al. Asian Academic Research Journal of Multidisciplinary. PLASMA ELECTRO-DYNAMIC DISCHARGE (PED) FOR SELF- CLEANING of DUST IN SOLAR PANELS, Reviewed International Journal of Asian 2016; 3 (6).

11. Rietema K. The Dynamics of Fine Powders Elsevier, UK. 1990. https://doi.org/10.1007/978-94-011-3672-3

12. Zhu J, et al. Nanodome solar cells with efficient light management and self-cleaning, Nano-Letter. 2010; 10: 1979- 1984.

https://doi.org/10.1021/n19034237 